\title{
OFICINAS DE FORMAÇÃO SOBRE PRODUÇÃO DE TEXTOS: UMA EXPERIÊNCIA COM PROFESSORES DO ENSINO FUNDAMENTAL
}

\author{
Ana Luzia Videira Parisotto \\ Universidade Estadual Paulista - UNESP, Departamento de Educação, Presidente Prudente, SP. e-mail: \\ analu.videira@uol.com.br
}

\section{RESUMO}

Este trabalho originou-se de uma pesquisa maior, financiada pelo Conselho Nacional de Desenvolvimento Científico e Tecnológico (CNPq), que objetivou investigar processos de aprendizagem profissional de professores e formadores da Educação Básica de uma escola municipal e as contribuições de um programa de desenvolvimento profissional construído e implementado colaborativamente no local de trabalho. Neste artigo serão observados os dados relacionados ao ensino de Língua Portuguesa (produção textual), no que diz respeito às oficinas formativas, com o objetivo de propiciar reflexão sobre a formação docente. É uma pesquisa qualitativa do tipo colaborativa. Os resultados apontam a importância de se levar em consideração as necessidades de formação explicitadas pelo professor em seu contexto de trabalho, uma vez que há interesse pela formação, todavia nem sempre há disponibilidade para a realização das atividades previstas nos processos formativos devido ao excesso de demandas da escola.

Palavras-chave: Formação Docente, Ensino de Língua Portuguesa, Produção Textual, Oficinas de Formação, Pesquisa Colaborativa.

\section{TEXT PRODUCTION WORKSHOPS: AN EXPERIMENT WITH ELEMENTARY SCHOOL TEACHERS}

\begin{abstract}
As part of a broader research project funded by the National Council for Scientific and Technological Development (CNPq), this study aims to investigate professional learning processes of schoolteachers and educators from a municipal elementary school and examine the contributions of a professional development program collaboratively constructed and implemented at the workplace. This article analyzes and discusses the data concerning the teaching of Portuguese (text production) in connection with training workshops intended for promoting reflection on teacher education. Results from this qualitative-collaborative research point to the importance of taking into account teachers' training needs elicited at their workplace, since despite their interest in training, it is not always possible to carry out the activities envisaged for the formative processes due to overwhelming school demands.

Keywords: Teacher Education, Teaching of Portuguese, Text Production, Formative Workshops, Collaborative Research.
\end{abstract}




\section{INTRODUÇÃO}

Torna-se essencial observar as demandas da sociedade como parâmetros para o desenvolvimento das atividades escolares. Não obstante a formação não pode mais ser vista como capaz de dotar as pessoas de uma bagagem fixa de conhecimentos a serem utilizados por toda a vida. Há que se pensar em uma formação de base, voltada para o favorecimento da flexibilidade e adaptação exigidas, considerando-se o contexto desafiador de superação das desigualdades (GATTI, 2013, TARDIF, 2002; IMBERNÓN, 2010; VEIGA, 2002).

Sobre a formação de professores no Brasil, Pereira (2000) afirma que, enquanto na década de 1970 enfatizava-se a dimensão técnica do processo de formação de professores, na década de 1980 houve um avanço nessa questão, já que a preocupação estava voltada para a formação em serviço. Todavia, a partir de 1990, começa a surgir uma outra perspectiva para a formação docente: a educação continuada.

Segundo Garcia (1999), a educação continuada está relacionada ao desenvolvimento profissional dos professores num processo de evolução e continuidade, não se encaixando na definição tradicional de algo que seja uma justaposição entre a formação inicial e o aperfeiçoamento.
Dessa forma, a formação de professores configura-se como uma área de investigação que se debruça sobre os processos por meio dos quais os professores aprendem a ser professor e ampliam suas habilidades e saberes profissionais. Imbernón (2010) destaca a necessidade de se desenvolver uma nova perspectiva na formação continuada de professores, que não separe a formação do contexto de trabalho, pois esse contexto, segundo o autor, é que deve condicionar as práticas formativas.

As pesquisas acerca da formação de professores mobilizam vários profissionais, não só os da área da educação, mas também os linguistas, já que a pertinência desse tema reside na sua estreita relação com o sucesso ou o fracasso escolar. Nesse sentido, foi desenvolvido um projeto de pesquisaintervenção que objetivou, por meio da análise documental e da adoção de uma abordagem construtivo-colaborativa, tendo o questionário e as narrativas escritas como principais instrumentos de coleta de dados, avaliar as contribuições de um programa de desenvolvimento profissional construído e implementado no contexto da escola para melhoria do ensino e da atuação de professores e gestores. $O$ estudo foi desenvolvido em uma escola pública de Educação Básica, localizada em um bairro periférico considerado como sendo de 
exclusão social, no município de Presidente Prudente/SP e envolveu pesquisadores de duas universidades paulistas. A partir dos resultados da investigação geral instituiu-se um recorte na totalidade dos dados, destacando aqueles relativos ao ensino da produção de texto. Realizaram-se oficinas de formação, considerando os conteúdos elencados pelos professores como necessários e urgentes para serem trabalhados, bem como outros que surgiram após a tabulação e apresentação dos resultados do questionário, cujos temas versaram sobre: língua, linguagem, leitura, produção textual, texto, coesão e coerência textuais, dificuldades relacionadas ao ensino do texto, avaliação de texto, dentre outros.

O objetivo deste artigo é refletir sobre a formação docente, apresentando e discutindo os dados relativos à avaliação das oficinas de formação sobre produção textual, realizada pelos docentes que delas participaram.

\section{METODOLOGIA}

A pesquisa foi desenvolvida segundo a abordagem qualitativa que procura explicar em profundidade as características e os significados das informações obtidas (OLIVEIRA, 2007).

Nesse caso, optamos pela pesquisa colaborativa que, conforme Ibiapina (2008), envolve:
[...] investigadores $\mathrm{e}$ professores tanto em processos de produção de conhecimentos quanto de desenvolvimento interativo da própria pesquisa, haja vista que o trabalho colaborativo faz com que professores pesquisadores produzam saberes, compartilhando estratégias que promovem desenvolvimento profissional.

A pesquisa colaborativa estabelece um diálogo entre pesquisadores, professores e gestores, enfatizando a investigação, a construção de novos conhecimentos, bem como a busca de soluções para problemas concretos do cotidiano escolar.

O acompanhamento dos trabalhos dos professores, ao longo do desenvolvimento da pesquisa, foi realizado por meio de reuniões, questionários e entrevistas.

A análise preliminar dos questionários forneceu-nos subsídios para propor um curso de extensão intitulado "O ensino da produção textual", cadastrado sob o nㅇ 5446, na Pró-Reitoria de Extensão Universitária (PROEX/ UNESP), com trinta e duas horas de duração, ministrado sob a forma de oficinas de formação.

Nesse sentido, estabelecemos, juntamente com os sujeitos envolvidos, um cronograma que previa encontros semanais com os seguintes objetivos: dar continuidade 
à formação do professor, propiciando reflexão sobre a linguagem; ampliar e aprofundar conceitos de texto, leitura, coesão, coerência, gênero textual e avaliação de textos. O curso teve início em 5/9/2012 e foi finalizado em 31/10/2012.

Na medida do possível, empenhamonos para trabalhar colaborativamente com vistas às demandas apresentadas pelos professores no espaço de tempo e de acordo com os objetivos estabelecidos pela pesquisa. Ibiapina (2008) destaca três elementos essenciais para a condução de pesquisas colaborativas: a co-produção de conhecimento, o uso dessa prática de investigação como estratégia de formação e desenvolvimento profissional e a mudança das práticas educativas via mediação do pesquisador. Acreditamos que tal experiência tenha sido colaborativa na medida em que possibilitou algumas mudanças nas práticas educativas, principalmente naquelas relacionadas ao trabalho com o gênero carta de leitor. Quanto à co-produção de conhecimento, convidamos alguns docentes a colaborarem na elaboração de artigos sobre a pesquisa, porém pelo excesso de atribuições que haviam assumido para o segundo semestre de 2012 não houve interesse.

O projeto foi avaliado e aprovado pelo Comitê de Ética em Pesquisa (CEP/Unoeste), sob número 456/OL, novembro de 2010.

\section{RESULTADOS}

Para este artigo, apresentamos os resultados obtidos por meio de um questionário de avaliação das oficinas de formação das quais participaram cinco docentes do Ensino Fundamental, de uma escola municipal de Presidente Prudente, conforme pode ser verificado no Quadro 1.

As questões que compuseram o questionário versavam sobre: consistência e coerência dos conteúdos abordados com relação à formação do professor dos anos iniciais; dificuldades ou facilidades de realização das atividades propostas; contribuições das oficinas para aprimorar conhecimento; adequação da carga horária do curso e do horário dos encontros; realização da leitura dos textos propostos para discussão nas oficinas. Vale ressaltar que as leituras deveriam ser realizadas fora do horário regular das oficinas. 
Quadro 1. Avaliação das oficinas de formação docente

\begin{tabular}{|c|c|c|c|c|c|c|c|}
\hline Docente & $\begin{array}{l}\text { Avaliação } \\
\text { geral do } \\
\text { curso }\end{array}$ & $\begin{array}{l}\text { Consistência } \\
\text { e coerência } \\
\text { dos } \\
\text { Conteúdos } \\
\text { abordados }\end{array}$ & $\begin{array}{l}\text { Dificuldades } \\
\text { e facilidades } \\
\text { para realizar } \\
\text { atividades } \\
\text { propostas }\end{array}$ & $\begin{array}{l}\text { Aprimoramento } \\
\text { de } \\
\text { conhecimento }\end{array}$ & $\begin{array}{l}\text { Adequação } \\
\text { da Carga } \\
\text { horária e } \\
\text { do horário } \\
\text { dos } \\
\text { encontros }\end{array}$ & $\begin{array}{l}\text { Leitura dos } \\
\text { textos } \\
\text { propostos }\end{array}$ & $\begin{array}{l}\text { Sugestões } \\
\text { de outras } \\
\text { oficinas/ } \\
\text { cursos }\end{array}$ \\
\hline D1 & ótimo & $\begin{array}{l}\text { - Foram } \\
\text { apresentado } \\
\text { s de forma } \\
\text { consistente; } \\
\text { - são } \\
\text { coerentes } \\
\text { com a } \\
\text { formação do } \\
\text { professor } \\
\text { das séries } \\
\text { iniciais; }\end{array}$ & $\begin{array}{l}\text { - não } \\
\text { realizei } \\
\text { todas as } \\
\text { atividades } \\
\text { propostas, } \\
\text { mas não } \\
\text { senti } \\
\text { dificuldade } \\
\text { naquelas } \\
\text { que realizei }\end{array}$ & $\begin{array}{l}\text {-Linguagem } \\
\text { - Língua } \\
\text { - Gêneros } \\
\text { textuais } \\
\text { - tipos textuais } \\
\text { - produção de } \\
\text { texto }\end{array}$ & $\begin{array}{l}\text { - } \\
\text { adequados, } \\
\text { porém } \\
\text { duas horas } \\
\text { de duração } \\
\text { para cada } \\
\text { encontro } \\
\text { foi } \\
\text { insuficiente } \\
\text { para o } \\
\text { aprofunda } \\
\text { mento de } \\
\text { alguns } \\
\text { conteúdos. }\end{array}$ & $\begin{array}{l}\text { - Li } \\
\text { superficialmen } \\
\text { te, pois tive } \\
\text { que priorizar } \\
\text { outras } \\
\text { atividades com } \\
\text { prazos mais } \\
\text { apertados. }\end{array}$ & - \\
\hline D2 & ótimo & $\begin{array}{l}\text { - Foram } \\
\text { apresentado } \\
\text { s de forma } \\
\text { consistente; } \\
\text { - são } \\
\text { coerentes } \\
\text { com a } \\
\text { formação do } \\
\text { professor } \\
\text { das séries } \\
\text { iniciais; }\end{array}$ & $\begin{array}{l}\text { - Facilidade: } \\
\text { análise e } \\
\text { correção de } \\
\text { um } \\
\text { reconto/ree } \\
\text { scrita, pois } \\
\text { foi muito } \\
\text { explicado no } \\
\text { último } \\
\text { encontro. } \\
\text { - } \\
\text { Dificuldade: } \\
\text { elaborar o } \\
\text { relato de } \\
\text { experiência, } \\
\text { pois sinto } \\
\text { dificuldade } \\
\text { de falar e } \\
\text { escrever } \\
\text { sobre } \\
\text { assuntos } \\
\text { pessoais. }\end{array}$ & $\begin{array}{l}\text { - Linguagem; } \\
\text { - gêneros } \\
\text { textuais; } \\
\text { - coesão e } \\
\text { coerência; } \\
\text { - leitura; } \\
\text { - produção de } \\
\text { texto. }\end{array}$ & $\begin{array}{l}\text { - horário } \\
\text { do curso } \\
\text { foi } \\
\text { adequado; } \\
\text { - deveria } \\
\text { ter uma } \\
\text { carga } \\
\text { horária } \\
\text { maior. }\end{array}$ & $\begin{array}{l}\text { - Li } 80 \% \text { dos } \\
\text { textos. } \\
\text {-Tive } \\
\text { dificuldade em } \\
\text { conciliar as } \\
\text { leituras com } \\
\text { outras } \\
\text { atividades. }\end{array}$ & $\begin{array}{l}\text { - curso } \\
\text { sobre } \\
\text { produção } \\
\text { textual com } \\
\text { carga } \\
\text { horária } \\
\text { maior. }\end{array}$ \\
\hline D3 & ótimo & $\begin{array}{l}\text { - Foram } \\
\text { apresentado } \\
\text { s de forma } \\
\text { consistente; } \\
\text { - são } \\
\text { coerentes } \\
\text { com a } \\
\text { formação do } \\
\text { professor } \\
\text { das séries } \\
\text { iniciais; }\end{array}$ & $\begin{array}{l}\text { Não } \\
\text { consegui } \\
\text { realizar } \\
\text { nenhuma } \\
\text { atividade. }\end{array}$ & $\begin{array}{l}\text { - Linguagem } \\
\text { - Língua } \\
\text { - gêneros } \\
\text { textuais, } \\
\text { - tipos textuais; } \\
\text { - coesão e } \\
\text { coerência } \\
\text { textuais }\end{array}$ & $\begin{array}{l}\text { - horário } \\
\text { do curso } \\
\text { foi } \\
\text { adequado, } \\
\text { pois o } \\
\text { período } \\
\text { noturno é a } \\
\text { única } \\
\text { forma de } \\
\text { atender os } \\
\text { professores } \\
\text { dos dois } \\
\text { períodos. } \\
\text { - carga } \\
\text { horária } \\
\text { maior. }\end{array}$ & $\operatorname{sim}$ & $\begin{array}{l}\text { Aprofundar } \\
\text { o trabalho } \\
\text { com } \\
\text { produção } \\
\text { de textos. }\end{array}$ \\
\hline
\end{tabular}




\begin{tabular}{|c|c|c|c|c|c|c|c|}
\hline D4 & ótimo & $\begin{array}{l}\text { - Foram } \\
\text { apresentado } \\
\text { s de forma } \\
\text { consistente; } \\
\text { - são } \\
\text { coerentes } \\
\text { com a } \\
\text { formação do } \\
\text { professor } \\
\text { das séries } \\
\text { iniciais; } \\
\text { - Facilitaram } \\
\text { a construção } \\
\text { de } \\
\text { conhecimen } \\
\text { tos para } \\
\text { aplicação } \\
\text { em sala de } \\
\text { aula. }\end{array}$ & $\begin{array}{l}\text { - Facilidade } \\
\text { para } \\
\text { elaboração } \\
\text { das } \\
\text { atividades. } \\
\text { - dificuldade } \\
\text { de ler todos } \\
\text { os textos. }\end{array}$ & $\begin{array}{l}\text { - linguagem; } \\
\text { - língua; } \\
\text { - tipos textuais; } \\
\text { - coesão e } \\
\text { coerência } \\
\text { textuais; }\end{array}$ & $\begin{array}{l}\text { A carga } \\
\text { horária do } \\
\text { curso foi } \\
\text { adequada, } \\
\text { mas como } \\
\text { era fora do } \\
\text { horário de } \\
\text { trabalho, } \\
\text { acabei } \\
\text { faltando } \\
\text { em alguns } \\
\text { encontros. }\end{array}$ & $\begin{array}{l}\text { - Não consegui } \\
\text { ler todos os } \\
\text { textos, pois } \\
\text { estive } \\
\text { envolvida com } \\
\text { preparação de } \\
\text { aulas e } \\
\text { trabalhos da } \\
\text { faculdade. }\end{array}$ & $\begin{array}{l}\text { - } \\
\text { organizaçã } \\
\text { o do } \\
\text { currículo } \\
\text { de Língua } \\
\text { Portuguesa } \\
\text { do 10 ao 5o } \\
\text { ano; - } \\
\text { Interpretaç } \\
\text { ão de } \\
\text { textos; } \\
\text { - Leitura. }\end{array}$ \\
\hline D5 & ótimo & $\begin{array}{l}\text { - Foram } \\
\text { apresentado } \\
\text { s de forma } \\
\text { consistente; } \\
\text { - Facilitaram } \\
\text { a construção } \\
\text { de } \\
\text { conhecimen } \\
\text { tos para } \\
\text { aplicação } \\
\text { em sala de } \\
\text { aula. }\end{array}$ & $\begin{array}{l}\text { - facilidade } \\
\text { na } \\
\text { elaboração } \\
\text { do relato de } \\
\text { experiência. } \\
\text { - dificuldade } \\
\text { para ler os } \\
\text { textos } \\
\text { propostos, } \\
\text { por causa da } \\
\text { falta de } \\
\text { tempo. }\end{array}$ & $\begin{array}{l}\text { - coesão e } \\
\text { coerência } \\
\text { textuais; } \\
\text { - produção de } \\
\text { textos. }\end{array}$ & $\begin{array}{l}\text { - Foram } \\
\text { adequados: } \\
\text { carga } \\
\text { horária do } \\
\text { curso e } \\
\text { horário do } \\
\text { curso. }\end{array}$ & $\begin{array}{l}\text { Não. } \\
\text { Dificuldade em } \\
\text { conciliar as } \\
\text { atividades de } \\
\text { trabalho com } \\
\text { as leituras. }\end{array}$ & $\begin{array}{l}\text { - } \\
\text { Interpretaç } \\
\text { ão de } \\
\text { texto. } \\
\text { - como } \\
\text { corrigir as } \\
\text { redações. }\end{array}$ \\
\hline
\end{tabular}

\section{DISCUSSÃO}

Com relação à avaliação geral do curso/oficinas, as docentes consideraram-no ótimo, talvez porque tenha partido das necessidades de formação que elas apresentaram por meio do questionário inicial e das conversas que tivemos por ocasião das reuniões das quais participamos na escola. Nesse sentido, Imbernón (2010) destaca a necessidade de uma rearmada moral e intelectual dos professores, que passe pelo controle sobre o seu processo de trabalho, incluindo a sua formação.
No que diz respeito à consistência e coerência dos conteúdos abordados para a formação do professor que leciona nos anos iniciais, as professoras afirmaram que os conteúdos foram apresentados de forma consistente, quatro docentes responderam que são coerentes com a formação docente para a etapa de ensino em que lecionam e duas destacaram que os conteúdos abordados facilitaram a construção de conhecimentos para aplicação em sala de aula. Sobre aplicar o conhecimento em sala de aula, Imbernón (2010) afirma que um indivíduo, no caso o professor, pode 
aprender questões concretas, mas muito distantes de suas preocupações práticas e, nesse sentido, pode não causar grandes impactos nas práticas de sala de aula.

A maioria das atividades propostas foi realizada pelas docentes. Destacamos, dentre essas atividades, aquelas cuja realização foi mais fácil: uma docente inseriu neste item atividade de avaliação de textos produzidos em situação escolar e outra docente manifestou que teve facilidade para elaborar o relato em que descreviam suas experiências como leitoras, produtoras de texto e como professoras que ensinam a ler e produzir textos. Por outro lado, houve uma docente que considerou difícil a atividade de elaboração do relato e duas manifestaram dificuldade para realizar as leituras propostas. Vale destacar que as atividades consideradas no questionário deveriam ser realizadas em casa e apresentadas durante as oficinas.

Nos aspectos atinentes às contribuições das oficinas para aprimorar conhecimentos, as docentes destacaram a relevância de se aprofundar conhecimentos relativos à: concepções de linguagem de língua, gêneros do discurso e tipos textuais, coesão e coerência, ensino de produção textual e de leitura. A articulação teoria e prática, preconizada por Garcia (1999), foi priorizada em atividades de estudo de textos teóricos e atividades práticas, envolvendo os conteúdos estudados e trabalhados pelas docentes nas aulas que ministravam a alunos do ensino fundamental I, reinterpretando a teoria com base na prática e vice-versa.

Quanto à carga horária das oficinas, três docentes afirmaram que deveria ser maior para que fosse possível aprofundar os conteúdos estudados e duas docentes consideraram-na adequada. Em contrapartida, a maioria das docentes acenou positivamente quanto ao horário dos encontros (período noturno), pensado no sentido de facilitar a participação delas. Alguns pesquisadores destacam a importância de se integrar os processos de formação de professores com o desenvolvimento organizacional da escola (GARCIA, 1999; IMBERNÓN, 2010). Nosso trabalho sempre foi pensado em conjunto com professores e gestores da unidade escolar pesquisada, respeitando o tempo e a disponibilidade dos sujeitos envolvidos nos processos formativos. Por conta de excesso de atividades, apenas uma docente afirmou que conseguiu realizar a leitura de todos os textos.

Elas sugerem que sejam oferecidos cursos sobre: produção de texto com carga horária maior, organização do currículo do 1으 ao 50 ano, interpretação de textos, leitura, avaliação de textos produzidos pelos alunos. Garcia (1999) enfatiza a necessidade de se integrar a formação de professores em 
processos de mudança, inovação e desenvolvimento curricular. $\mathrm{Na}$ escola pesquisada, professores e gestores têm sinalizado as incoerências na concepção de um currículo para o ensino fundamental, no município de Presidente Prudente. Nesse sentido, as docentes manifestam interesse em refletir sobre a organização do currículo para o ensino fundamental $\mathrm{I}$.

\section{CONCLUSÃO}

O papel do professor do ensino fundamental I, no sentido de ensinar o aluno, efetivamente, a ler e a escrever é de extrema relevância, por isso o conhecimento da Língua materna é fundamental para que percebam as possibilidades de atuar sobre o seu interlocutor, persuadi-lo, convencê-lo e isso só ocorre por meio da linguagem.

O processo de formação continuada de professores requer que se devolva a palavra aos sujeitos, para que, num processo dialógico, tornem-se responsáveis pela sua formação, considerando o seu contexto de trabalho.

Após o término desta pesquisa, outros projetos serão propostos, observando a realidade da escola parceira, pois já estabelecemos um vínculo por meio do qual estamos aproximando a universidade da escola, articulando as necessidades de formação docente e os interesses da produção acadêmica.

\section{REFERÊNCIAS}

GATTI, B. A. O trabalho docente: avaliação, valorização e controvérsias. São Paulo: Autores associados/Fundação Carlos Chagas, 2013.

IBIAPINA, I. M. L. M. Pesquisa colaborativa: investigação, formação e produção de conhecimentos. Brasília: Líber Livro, 2008.

IMBERNÓN, F. Formação continuada de professores. Porto Alegre: Artmed, 2010.

GARCIA, C. M. Formação de professores: para uma mudança educativa. Porto: Porto, 1999.

OLIVEIRA, M. M. Como fazer pesquisa qualitativa. Petrópolis: Vozes, 2007.

PEREIRA, J. E. D. Formação de professores: pesquisas, representações e poder. Belo Horizonte: Autêntica, 2000.

TARDIF, M. Saberes docentes e formação docente. Petrópolis: Vozes, 2002.

VEIGA, I. P. A. Professor: tecnólogo do ensino ou agente social? In: VEIGA, I. P. A.; AMARAL, A. L. (org.). Formação de professores políticas e debates. Campinas: Papirus, 2002.

Recebido para publicação em 17/07/2014 Revisado em 24/07/2014

Aceito em 18/08/2014 